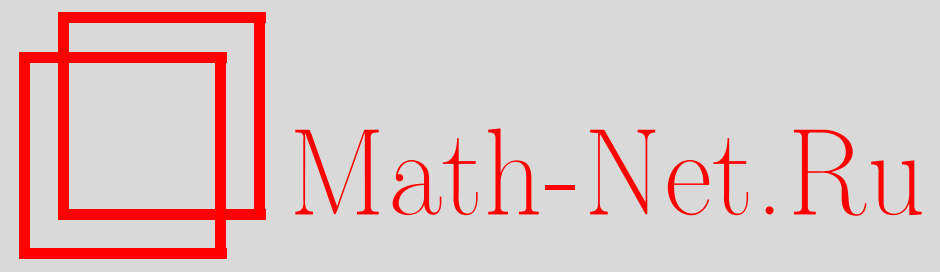

S. Louhichi, Rates of Convergence in the CLT for Some Weakly Dependent Random Variables, Teория вероятн. и ее примен., 2001, том 46, выпуск 2, 345364

DOI: https://doi.org/10.4213/tvp3922

Использование Общероссийского математического портала MathNet.Ru подразумевает, что вы прочитали и согласны с пользовательским соглашением

http://www . mathnet.ru/rus/agreement

Параметры загрузки:

IP : 34.229 .108 .108

26 апреля 2023 г., 13:55:11

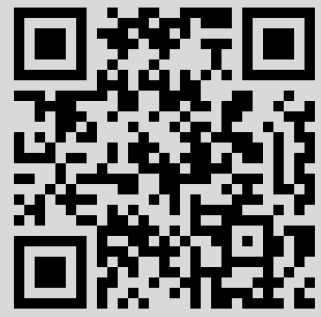




\title{
RATES OF CONVERGENCE IN THE CLT FOR SOME WEAKLY DEPENDENT RANDOM VARIABLES
}

\begin{abstract}
Устанавливается скорость сходимости в центральной предельной теореме для некоторых слабо зависимых последовательностей при условии степенного затухания ковариаций. Эти последовательности предполагаются ассоциированными или удовлетворяющими общему свойству гауссовских процессов и положительно (или отрицательно) зависимых случайных величин.

Мы распространяем на наш случай метод Линдеберга, следуя методу работы [21] для последовательностей с перемешиванием.

В ходе доказательства получены верхние границы для расстояния Дадли между распределением нормированной суммы слабо зависимых случайных величин и стандартным нормальным распределением, а также неравенства типа Розенталя для моментов частичных сумм.
\end{abstract}

Ключевые слова и фразы: ассоциированность, положительная зависимость, отрицательная зависимость, теорема Берри-Эссеена, центральная предельная теорема Линдеберга, моментные неравенства, неравенства Розенталя.

1. Introduction and notation. Let $\left(X_{n}\right)_{n \in Z}$ be a sequence of associated random variables (r.v.'s), i.e., for every finite subcollection $X_{i_{1}}, \ldots, X_{i_{n}}$ and every pair of coordinatewise nondecreasing functions $h, k: \mathbf{R}^{n} \rightarrow \mathbf{R}$

$$
\operatorname{cov}\left(h\left(X_{i_{1}}, \ldots, X_{i_{n}}\right), k\left(X_{i_{1}}, \ldots, X_{i_{n}}\right)\right) \geqslant 0,
$$

whenever the covariance is defined. This definition was introduced by Esary, Proschan, and Walkup [13], mainly for the sake of applications in reliability and statistics.

In the following we assume that $X_{i}=0$ for $i \leqslant 0, \mathbf{E} X_{i}=0$ and $\mathbf{E} X_{i}^{2}<\infty$. We put $S_{n}=X_{1}+\cdots+X_{n}, S_{0}=0, V_{n}=\mathbf{D} S_{n}$. We suppose without loss of generality that $\left|\operatorname{cov}\left(X_{i}, X_{j}\right)\right| \leqslant 1$ for all $i, j \in \mathbf{N}$. Finally, we denote by $\pi_{n}$ the deviation of the distribution of $S_{n} / \sqrt{V_{n}}$ from the normal law, that is

$$
\pi_{n}:=\sup _{x \in \mathbf{R}}\left|\mathbf{P}\left\{\frac{S_{n}}{\sqrt{V_{n}}} \leqslant x\right\}-\psi(x)\right|
$$

${ }^{*}$ Université de Paris-Sud, Probabilités, statistique et modélisation, Bât. 425, 91405 Orsay Cedex, France; e-mail: Sana.Louhichi@math.u-psud.fr 
where $\psi$ denotes the distribution of a standard normal law. Bounds of $\pi_{n}$ are known as Berry-Esseen type estimates. The first Berry-Esseen type estimation under association was given by Wood [26]. He obtained a rate of order $O\left(n^{-1 / 5}\right)$. Wood's rate is far from the optimal Berry-Esseen's rate $O\left(n^{-1 / 2}\right)$ (see [18]).

The best possible rate for association was obtained by Birkel [3]. He obtained a rate of order $O\left(n^{-1 / 2} \ln n\right)$ if the associated sequence has a finite moment of order $(3+\rho)$, if $\inf _{n} V_{n} / n>0$ and if the sequence $U(n)$ defined by $U(n)=\sup _{k \in \mathrm{N}} \sum_{j:|j-k| \geqslant n} \operatorname{cov}\left(X_{j}, X_{k}\right)$ decreases exponentially fast to 0 . Recently, Bulinski [4], [6], [7] gave Berry-Esseen type estimates for associated random fields.

The main task of this paper is to study the behavior of $\pi_{n}$ under a power decay of the covariance of the associated process. We cannot expect the Berry-Esseen rate $O\left(n^{-1 / 2}\right)$, since an example in [3] shows that a rate of order $O\left(n^{-1 / 2} \ln n\right)$ cannot be obtained under an hyperbolic decay of $U(n)$.

We prove that $\pi_{n}=O\left(n^{-1 / 3}\right)$, if $\inf _{n} V_{n} / n>0, \sup _{i \geqslant 0}\left\|X_{i}\right\|_{3+\rho}<\infty$ and if

$$
\sup _{k \geqslant 0} \sum_{i=1}^{\infty} i \operatorname{cov}^{1-1 / q}\left(X_{k}, X_{k-i}\right)<\infty
$$

hold for some $\rho>0,1<q<1+\rho$ (here and in the sequel $\|X\|_{p}$ denotes $\left.\left(\mathbf{E}|X|^{p}\right)^{1 / p}\right)$. We do not know whether this rate is optimal, but we note that also for bounded mixing sequences, Rio [21] obtained the convergence rate $O\left(n^{-1 / 3}\right)$ under the condition $\sum_{i=1}^{\infty} i \alpha_{i}<\infty$, where $\left(\alpha_{i}\right)_{i \in \mathbf{N}}$ denotes the strong mixing coefficients introduced by Rosenblatt [23].

If moreover the sequences are bounded, then the condition of association on the processes may be weakened. In fact, we only assume that the sequence $\left(X_{n}\right)_{n \in \mathbf{N}}$ satisfies the following property.

$\mathrm{D}$ e $\mathrm{f}$ in it i o 1 . A sequence $\left(X_{n}\right)_{n \in \mathbf{N}}$ is said to be (AG) if there exists a sequence $\left(\tilde{X}_{n}\right)_{n \in \mathbf{N}}$ of r.v.'s such that $\mathbf{D} X_{i} \leqslant \mathbf{D} \tilde{X}_{i}$, for all $i \in \mathbf{N}$, and

$$
\left|\operatorname{cov}\left(h\left(X_{i}, i \in A\right), k\left(X_{j}, j \in B\right)\right)\right| \leqslant \sum_{i \in A} \sum_{j \in B}\left\|\frac{\partial h}{\partial x_{i}}\right\|_{\infty}\left\|\frac{\partial k}{\partial x_{j}}\right\|_{\infty}\left|\operatorname{cov}\left(\tilde{X}_{i}, \tilde{X}_{j}\right)\right|
$$

holds for all disjoint finite subsets $A$ and $B$ of $\mathbf{N}$ and for all functions $h$ and $k$ having bounded first differentials.

This property is known to hold for Gaussian and associated sequences (cf., for example, [3] and [11]). We call the previous inequality the (AG) property. Random variables satisfying the (AG) property will be called (AG) r.v.'s.

Since associated sequences satisfy the (AG) property with $\left(X_{n}\right)=\left(\widetilde{X}_{n}\right)$ (cf. Lemma 3-1 in [3]), we deduce that for an associated sequence $\left(X_{n}\right)_{n \in \mathbf{N}}$, the sequence $\left(g\left(X_{n}\right)\right)_{n}$ satisfies also the (AG) property with $\left(\tilde{X}_{n}\right)=$ $\left(\left\|g^{\prime}\right\|_{\infty} X_{n}\right)\left(g^{\prime}\right.$ denotes the first derivative of the real-valued function $\left.g\right)$. 
The (AG) property with $\left(X_{n}\right)=\left(\tilde{X}_{n}\right)$ is also satisfied by negatively dependent r.v.'s (cf. [7]); we recall that the sequence $\left(X_{n}\right)_{n \in \mathbf{N}}$ is negatively dependent if for all coordinatewise nondecreasing real-valued functions $h$ and $k$

$$
\operatorname{cov}\left(h\left(X_{i}, i \in A\right), k\left(X_{i}, i \in B\right)\right) \leqslant 0
$$

holds for all finite and disjoint subsets $A$ and $B$ of $\mathbf{N}$. We refer to [14] for more about this notion of negative dependence.

Contrary to mixing, this class of weakly dependent processes does not directly involve $\sigma$-algebras generated, but their dependence structure is contained in second order properties. This means that orthogonality is equivalent to independence. Notice that such sequences are special weakly dependent sequences as defined in [11]. This implies that nontrivial adaptations are necessary here to adapt Rio's [21] method (for strongly mixing sequences) in Lindeberg theorem.

For (AG) sequences bounded by $M$, we obtain a convergence rate $O\left(n^{-\delta / 3}\right)$, if $0<\delta \leqslant 1$ and if

$$
\sup _{k \geqslant 0} \sum_{i=1}^{\infty} i^{\delta}\left|\operatorname{cov}\left(\tilde{X}_{k}, \tilde{X}_{k-i}\right)\right|<\infty .
$$

Also a convergence rate $O\left((\ln n)^{-p / 3}\right)$ holds if

$$
\sup _{k \geqslant 0} \sum_{i=1}^{\infty} \frac{\phi(M(i+1))}{(M(i+1))^{2}}\left|\operatorname{cov}\left(\tilde{X}_{k}, \tilde{X}_{k-i}\right)\right|<\infty,
$$

for some function $\phi$ in $\Phi$ verifying for some $p>0, \phi(x) \sim x^{2} \ln ^{p}(x)$ as $x \rightarrow \infty$, where $\Phi$ is the class of twice differentiable Orlicz functions defined by

$$
\begin{aligned}
\Phi=\left\{\phi: \mathbf{R}^{+} \rightarrow \mathbf{R}^{+} ;\right. & \phi \text { is convex, } \phi(0)=\phi^{\prime}(0)=0, \\
& \left.\phi^{\prime \prime} \text { is nondecreasing, concave }\right\} .
\end{aligned}
$$

(See Theorem 1 below.)

The method of the proofs which is based on Lindeberg decomposition provides upper bounds of the Dudley distance between the distribution of $S_{n} / \sqrt{V_{n}}$ and the standard normal distribution. We recall that the Dudley distance $d_{3}(X, Y)$ between the distributions of two realvalued r.v.'s $X$ and $Y$ is defined by $d_{3}(X, Y)=\sup |\mathbf{E}(f(X)-f(Y))|$, where the supremum is taken over all $C^{(3)}$ functions on $\mathbf{R}$ such that $\sup _{x \in \mathbf{R}} \max \left(\left|f^{\prime}(x)\right|,\left|f^{(2)}(x)\right|,\left|f^{(3)}(x)\right|\right) \leqslant 1$ (see [19] also [20]). In particular, we obtain for nondegenerate sequences of centered and associated r.v.'s having finite moment of order $(3+\rho)$

$$
\begin{aligned}
& d_{3}\left(\frac{S_{n}}{\sqrt{V_{n}}}, Y\right) \\
& \quad \leqslant C\left(\frac{1}{\sqrt{n}}+n V_{n}^{-1-(2+\rho) /(2(3+\rho))} \sum_{i=1}^{n-1} i \sup _{k} \operatorname{cov}^{1-1 / q}\left(X_{k}, X_{k-i}\right)\right),
\end{aligned}
$$


where $1<q<1+\rho$ and $C$ denotes a positive constant not depending on $n$ (cf. Theorem 4). For bounded, (AG) and weakly stationary sequences, we obtain

$$
\begin{aligned}
d_{3}\left(\frac{S_{n}}{\sqrt{V_{n}}}, Y\right) \leqslant & C\left\{\frac{1}{\sqrt{n}}+\frac{1}{V_{n}} \sum_{i=1}^{n-1} i\left|\operatorname{cov}\left(X_{1}, X_{1+i}\right)\right|\right. \\
& \left.+\frac{n}{V_{n}} \sum_{i=0}^{n-1} \min \left(1,(i+1) \frac{M}{\sqrt{V_{n}}}\right) \sup _{k}\left|\operatorname{cov}\left(\widetilde{X}_{k}, \widetilde{X}_{k-i}\right)\right|\right\},
\end{aligned}
$$

in this case the constant $C$ is universal. Such bounds are useful in the study of Berry-Esseen estimates of triangular arrays of (AG) sequences, such as the study of the asymptotic normality of kernel estimators of associated r.v.'s.

Finally, we prove Rosenthal type inequalities of order $r \in] 2,3]$ for bounded sequences of (AG) r.v.'s (cf. Proposition 1). The main interest of those inequalities is that they give the right bound for integrated moments of nonparametric estimators (see [9] for more about).

We conclude this section with some remarks concerning the Lindeberg method (cf. [15]).

This method was adapted by several authors in order to obtain central limit theorems for triangular arrays. In the mixing setting it was first used by Doukhan and Portal [10]. They studied the rates of convergence in the multidimensional central limit theorem. Adapting the Lindeberg method, Rio [22] obtained the optimal Berry-Esseen rate for a class of weakly dependent r.v.'s (see also [21]). Recently, Dedecker [8] uses this approach to prove a CLT for stationary random fields under a projective criterion.

This paper is organized as follows. In the next section, we give the main results. Theorems 1 and 2 deal with the Berry-Esseen estimation under association and the (AG) property. Theorems 3 and 4 give upper bounds of the Dudley distances under the weak dependence previously considered. The proofs of the main results are given in Section 3. Proposition 2 is the main tool for the proofs. An Appendix is dedicated to prove this proposition.

\section{Main results.}

Theorem 1. Let $\left(X_{n}\right)_{n \in \mathbf{N}}$ be a sequence of (AG) r.v.'s. Suppose that $\left(X_{n}\right)_{n \in \mathbf{N}}$ is bounded by $M$ and that

$$
\exists n_{0} \in \mathbf{N}^{*} \text { such that } \sigma^{2}=\sigma_{n_{0}}^{2}:=\inf _{\left\{n \geqslant n_{0}, 0 \leqslant k<n\right\}} \frac{V_{n}-V_{k}}{n-k}>0 .
$$

(i) If condition (3) holds for some $\delta \in] 0,1]$, then, for any $n \geqslant n_{0}$

$$
\sup _{x \in \mathbf{R}}\left|\mathbf{P}\left\{\frac{S_{n}}{\sqrt{V_{n}}} \leqslant x\right\}-\psi(x)\right|=O\left(n^{-\delta / 3}\right) .
$$

(ii) Suppose now that condition (4) holds for some function $\phi$ in $\Phi$ (defined by (5)) verifying for some positive $p, \phi(x) \sim x^{2} \ln ^{p}(x)$ as $x \rightarrow \infty$. 
Then

$$
\sup _{x \in \mathbf{R}}\left|\mathbf{P}\left\{\frac{S_{n}}{\sqrt{V_{n}}} \leqslant x\right\}-\psi(x)\right|=O\left((\ln n)^{-p / 3}\right) .
$$

$\mathrm{R}$ e $\mathrm{m}$ a $\mathrm{r} \mathrm{k} 1$. In the mixing case, the order obtained $O\left(n^{-\delta / 2}\right)$ is close to the optimal rate (cf. Theorem 2 in [21]). The exponent $\delta / 2$ is here replaced by $\delta / 3$ : the loss is due to the (AG) property (cf. Lemma 2 below).

$\mathrm{R}$ e $\mathrm{m}$ a $\mathrm{rk} 2$. There is a connection between an estimate of the logarithm rate in the central limit theorem and the law of the iterated logarithm, i.e., the relation

$$
\varlimsup_{n \rightarrow \infty}\left(2 V_{n} \ln \ln V_{n}\right)^{-1 / 2} S_{n}=1 \quad \text { a.s. }
$$

as it can be seen from Theorem 7.2 in [18] (cf. also [5] or [12]).

For unbounded and associated sequences, we obtain the following BerryEsseen estimates.

Theorem 2. Let $\left(X_{n}\right)_{n \in \mathbf{N}}$ be a sequence of centered and associated r.v.'s satisfying (8). Suppose that there exist some constants $\rho>0$ and $q \in] 1,1+\rho[$ such that condition (2) holds and that

$$
\sup _{i}\left\|X_{i}\right\|_{3+\rho}<\infty \text {. }
$$

Then

$$
\sup _{x \in \mathbf{R}}\left|\mathbf{P}\left\{\frac{S_{n}}{\sqrt{V_{n}}} \leqslant x\right\}-\psi(x)\right|=O\left(n^{-1 / 3}\right) .
$$

$\mathrm{R}$ e $\mathrm{m}$ a $\mathrm{rk} 3$. For associated sequence, condition (8) is satisfied as soon as

$$
\inf _{n \geqslant 1, k \geqslant 0} \frac{\mathbf{D}\left(S_{n+k}-S_{k}\right)}{n}>0,
$$

this follows from the inequality: $\mathbf{D}\left(S_{n+k}-S_{k}\right) \leqslant \mathbf{D} S_{n+k}-\mathbf{D} S_{k}$, proved for associated sequences. Condition (8) holds also if $\left(X_{n}\right)_{n \in \mathbf{N}}$ is a weakly stationary sequence such that $v_{k}:=V_{k}-V_{k-1}$ converges to a positive real number (see (3.7) and (3.8) of [21]).

$\mathrm{R}$ e $\mathrm{m}$ a $\mathrm{r} \mathrm{k}$. For bounded and associated sequences fulfilling (8), the bound (12) of Theorem 2 is obtained from (9) with $\delta=1$. In order to check this, only let $q$ tends to infinity in (2) (recall that associated sequences satisfy the $(\mathrm{AG})$ property with $\tilde{X}_{i}=X_{i}$ ).

$\mathrm{R}$ e $\mathrm{m}$ a $\mathrm{r} \mathrm{k}$ 5. Birkel [1] obtained the rate given by (9) for associated sequence $\left(X_{n}\right)_{n \in \mathbf{N}}$ fulfilling $\mathbf{E}\left(X_{i}\right)=0, \sup _{i} \mathbf{E}\left|X_{i}\right|^{3}<\infty, \inf _{n} V_{n} / n>0$ and

$$
\left.\left.\sup _{r \in \mathbf{N}} \operatorname{cov}\left(X_{r}, X_{r+n}\right)=O\left(n^{-2(3+2 \delta) /(3-2 \delta)}\right) \quad \text { for some } \delta \in\right] 0,1\right] \text {. }
$$

Clearly, condition (3) stated for bounded and associated sequences (see Theorem 1) improves (13). 
$\mathrm{R}$ e $\mathrm{m}$ a $\mathrm{r} \mathrm{k}$ 6. Bulinski [7] gave convergence rates in the CLT for positively and negatively dependent random fields under a power decrease of the correlation. For bounded and associated or negatively dependent sequences, Theorem 1 here improves on Bulinski's [7] results. Bulinski's results are however available for random fields having finite moments of order $s \in] 2,3]$ and also the summation is performed over finite sets of arbitrary configuration. Moreover, employing the Cox-Grimmett coefficient Bulinski demonstrates that his results are optimal, in a sense, for rapid power-type decay of covariance. Let us note that Bulinski's method is different from ours.

The next theorem provides upper bounds on the Dudley distances between the distribution of $S_{n} / \sqrt{V_{n}}$ and the standard normal distribution of $Y$.

Theorem 3. Let $\left(X_{n}\right)_{n \in \mathbf{N}}$ be a sequence of (AG) r.v.'s. Suppose moreover that $\left(X_{n}\right)_{n \in \mathbf{N}}$ is a weakly stationary sequence and uniformly bounded by $M$. Then there exists an universal positive constant $C$ for which the bound (7) holds.

It is possible to omit the stationarity assumption in the associated case, as it is proved by the forthcoming result.

Theorem 4. Let $\left(X_{n}\right)_{n \in \mathbf{N}}$ be a centered sequence of associated r.v.'s satisfying (8) and (11) for some $\rho>0$. Then for any $q \in] 1,1+\rho[$, there exists a positive constant $C$ not depending on $n$, for which inequality (6) holds.

$\mathrm{R}$ e $\mathrm{m} \mathrm{a} \mathrm{r} \mathrm{k} \mathrm{7.} \mathrm{Let} \mathrm{us} \mathrm{note} \mathrm{that} \mathrm{no} \mathrm{assumption} \mathrm{of} \mathrm{stationarity} \mathrm{is} \mathrm{re-}$ quired in Theorem 4. This is due to the inequality: $v_{k}=\mathbf{D} S_{k}-\mathbf{D} S_{k-1} \geqslant 0$, proved by using positive dependence (see the proof of Theorem 4).

An immediate application of Theorems 3 and 4 is the following.

Corollary 1. Let $\left(X_{n}\right)_{n \in \mathbf{N}}$ be a centered sequence of bounded r.v.'s. Suppose moreover that the weakly stationary sequence $\left(X_{n}\right)_{n \in \mathbf{N}}$ satisfies the (AG) property, (8) and (3) for some $\delta \in] 0,1]$. Then $\varlimsup_{n \rightarrow \infty} n^{\delta / 2} d_{3}\left(S_{n} / \sqrt{V_{n}}, Y\right)<\infty$.

Corollary 2. Let $\left(X_{n}\right)_{n \in \mathbb{N}}$ be a centered sequence of associated r.v.'s. Suppose that $\left(X_{n}\right)_{n \in \mathbf{N}}$ satisfies all the assumptions of Theorem 2 for some $\rho>0$ and $q \in] 1,1+\rho\left[\right.$. Then $\varlimsup_{n \rightarrow \infty} n^{(2+\rho) /(2(3+\rho))} d_{3}\left(S_{n} / \sqrt{V_{n}}, Y\right)<\infty$.

The next result is a moment inequality for the sum of bounded sequences satisfying the (AG) property. Let $s_{n}^{2}:=\sum_{i=1}^{n} \sum_{j=1}^{n}\left|\operatorname{cov}\left(X_{i}, X_{j}\right)\right|$.

Proposition 1. If the centered sequence $\left(X_{n}\right)_{n \in \mathbf{N}}$ is bounded by $M$ and satisfies the (AG) property, then for any $\phi \in \Phi(\Phi$ is defined by (5))

$$
\mathbf{E}\left(\phi\left(\left|S_{n}\right|\right)\right) \leqslant c\left(\phi\left(s_{n}\right)+\sum_{k=1}^{n} \sum_{i=1}^{k-1} \frac{\phi((i+1) M)}{(i+1)^{2} M^{2}}\left|\operatorname{cov}\left(\tilde{X}_{k}, \tilde{X}_{k-i}\right)\right|\right),
$$

where $c$ denotes an universal positive constant. 
$\mathrm{R}$ e m a r k 8. When $\phi(x)$ equals $x^{r}$ for $x \geqslant 0$ and for $\left.\left.r \in\right] 2,3\right]$, Proposition 1 yields a Rosenthal type inequality for negatively dependent r.v.'s (cf. [17] for such inequalities).

Proposition 1 applied to the centered sequence $\left(g\left(X_{n}\right)\right)_{n}$ when $\left(X_{n}\right)_{n \in \mathbf{N}}$ is an associated sequence and $g$ is a bounded function with a bounded first derivative, yields for $r \in] 2,3]$

$$
\mathbf{E}\left(\left|S_{n}(g)\right|^{r}\right) \leqslant c\left(s_{n}^{r}(g)+\sum_{k=1}^{n} \sum_{i=1}^{k-1}(i+1)^{r-2}\|g\|_{\infty}^{r-2}\left\|g^{\prime}\right\|_{\infty}^{2} \operatorname{cov}\left(X_{k}, X_{k-i}\right)\right),
$$

where

$$
S_{n}(g)=g\left(X_{1}\right)+\cdots+g\left(X_{n}\right), \quad s_{n}^{2}(g)=\sum_{i=1}^{n} \sum_{j=1}^{n}\left|\operatorname{cov}\left(g\left(X_{i}\right), g\left(X_{j}\right)\right)\right|
$$

This last inequality improves the corresponding one in [24] by a multiplicative factor $n^{\varepsilon}$. However the involved inequality (4.6) in [24] holds for any $r>2$ and any unbounded function $g$.

We refer to [25] for versions of Rosenthal inequality for associated random fields. Birkel's moment inequalities (cf. [2]) are also deduced from Proposition 1.

3. Proofs. The method of the proofs is based on Rio [21] but the details are quite different. The main step in Rio's proofs is to evaluate

$$
\Delta_{k}(f)=\mathbf{E}\left[f\left(S_{k}\right)-f\left(S_{k-1}\right)-\frac{v_{k}}{2} f^{\prime \prime}\left(S_{k-1}\right)\right],
$$

where $v_{n}=\mathbf{D} S_{n}-\mathbf{D} S_{n-1}$ and $f$ is a function that belongs to the set

$$
\mathscr{F}\left(b_{2}, b_{3}\right):=\left\{f: \mathbf{R} \rightarrow \mathbf{R} ;\left\|f^{\prime \prime}\right\|_{\infty} \leqslant b_{2},\left\|f^{(3)}\right\|_{\infty} \leqslant b_{3}\right\} .
$$

So the purpose of the following proposition is to control $\Delta_{k}(f)$ for associated or $(A G)$ sequences. All the results are shown to be deduced from the forthcoming proposition.

From now on, $C$ stands for a positive constant that does not depend on the considered sequence. It may, however, take different values in each appearance. Define, for some $p>1,\|X\|_{p}:=\sup _{i}\left\|X_{i}\right\|_{p}$.

Proposition 2. If the centered sequence $\left(X_{n}\right)_{n \in \mathbf{N}}$ is bounded by $M$ and satisfies the (AG) property, then for any function $f \in \mathscr{F}\left(b_{2}, b_{3}\right)$

$$
\left|\Delta_{k}(f)\right| \leqslant C \sum_{i=0}^{k-1} \min \left(b_{2}, b_{3}(i+1) M\right)\left|\operatorname{cov}\left(\tilde{X}_{k}, \tilde{X}_{k-i}\right)\right| .
$$

If $\left(X_{n}\right)_{n \in \mathbf{N}}$ is a sequence of centered and associated $r . v$.'s fulfilling (11) for some $\rho>0$, then for any $f \in \mathscr{F}\left(b_{2}, b_{3}\right)$ and for any $p, q$ such that $1<p<$ 
$(3+\rho)(1+\rho) /(2+\rho)$ and $1<q<1+\rho$, there holds

$$
\begin{aligned}
\left|\Delta_{k}(f)\right| \leqslant C\{ & b_{3}\|X\|_{3+\rho} \sum_{i=1}^{k-1} i \operatorname{cov}\left(X_{k}, X_{k-i}\right) \\
& +b_{3}\|X\|_{3+\rho}^{1+2 / q} \sum_{i=1}^{k-1} i \operatorname{cov}^{1-1 / q}\left(X_{k}, X_{k-i}\right) \\
& +b_{2}^{1 /(3+\rho)} b_{3}^{(2+\rho) /(3+\rho)}\|X\|_{3+\rho}^{2 / p+(2+\rho) /(3+\rho)} \\
& \left.\times \sum_{i=1}^{k-1} i \operatorname{cov}^{1-1 / p}\left(X_{k}, X_{k-i}\right)+b_{3} \mathbf{E}\left|X_{k}\right|^{3}\right\} .
\end{aligned}
$$

3.1. Berry-Esseen type estimates. We recall the notation (3.5) of [21]. For $m=[n / 3]$, let

$$
\begin{gathered}
\phi_{n, 1}=\phi_{m}:=\mathbf{E}\left(e^{i t S_{m}}\right), \quad \phi_{n, 2}=\mathbf{E}\left(e^{i t\left(S_{2 m}-S_{m}\right)}\right), \\
\phi_{n, 3}=\mathbf{E}\left(e^{i t\left(S_{n}-S_{2 m}\right)}\right), \quad \text { and } \quad V:=\mathbf{D} S_{m}+\mathbf{D}\left(S_{2 m}-S_{m}\right)+\mathbf{D}\left(S_{n}-S_{2 m}\right) .
\end{gathered}
$$

It follows from Esseen's inequality that for any $T>0$,

$$
\begin{aligned}
\sup _{x \in \mathbf{R}}\left|\mathbf{P}\left\{S_{n} \leqslant x\right\}-\psi\left(\frac{x}{\sqrt{V_{n}}}\right)\right| \leqslant C \int_{-T}^{T}\left|\frac{\phi_{n}(t)-\exp \left(-V t^{2} / 2\right)}{|t|}\right| d t \\
+\frac{C}{T \sqrt{V}}+\sup _{x \in \mathbf{R}}\left|\psi\left(\frac{x}{\sqrt{V}}\right)-\psi\left(\frac{x}{\sqrt{V_{n}}}\right)\right| .
\end{aligned}
$$

We first evaluate $\sup _{x \in \mathbf{R}}\left|\psi(x / \sqrt{V})-\psi\left(x / \sqrt{V_{n}}\right)\right|$. Inequality (3.25) of [21] yields, if (8) holds,

$$
\sup _{x \in \mathbf{R}}\left|\psi\left(\frac{x}{\sqrt{V}}\right)-\psi\left(\frac{x}{\sqrt{V_{n}}}\right)\right| \leqslant \frac{C}{n} \sum_{i=1}^{\infty} \min (i, n) \sup _{k \geqslant i}\left|\operatorname{cov}\left(X_{k}, X_{k-i}\right)\right| .
$$

Now define, for some $t$ in $\mathbf{R}^{+}$,

$$
M(t)=\sup _{k} \sum_{i=1}^{\infty} \min (t(i+1), 1)\left|\operatorname{cov}\left(\tilde{X}_{k}, \tilde{X}_{k-i}\right)\right| .
$$

The forthcoming lemma gives bounds of $M(t)$ as soon as the assumptions of Theorems 1 and 2 are fulfilled.

Lemma 1. Let $\left(X_{n}\right)_{n \in \mathbf{N}}$ be a sequence of (AG) r.v.'s. For $t$ small enough, the following properties hold.

1) If (3) holds for some $\delta \in] 0,1]$, then $M(t)=O\left(t^{\delta}\right)$.

2) If (4) holds for some $\phi$ in $\Phi$, then $M(t)=O\left(t^{-2} / \phi\left(M t^{-1}\right)\right)$. Hence $M(t)=O\left(|\ln t|^{-p}\right)$.

3) Suppose now that $\sup _{k} \sum_{i=1}^{\infty}(i+1)\left|\operatorname{cov}\left(\tilde{X}_{k}, \tilde{X}_{k-i}\right)\right|<\infty$. Then $M(t)=O(t)$.

P r o of. The proofs of 1) and 3) are immediate. The bound 2) follows from Lemma A.1 in [21]. 
From (18) and from some calculations like in Lemma 1, we deduce that $\sup _{x \in \mathbf{R}}\left|\psi(x / \sqrt{V})-\psi\left(x / \sqrt{V}_{n}\right)\right|$ has an order $O\left(n^{-\delta}\right)\left(\right.$ respectively, $O\left(\ln ^{-p} n\right)$ and $O\left(n^{-1}\right)$ ) if the (AG) sequence satisfies (3) (respectively, (4) and (2)).

Hence, taking into account Esseen's inequality, Theorems 1 and 2 are proved if we control $\left|\phi_{n}(t)-\exp \left(-V t^{2} / 2\right)\right|$. For this, write

$\left|\phi_{n}(t)-\exp \left(-\frac{V t^{2}}{2}\right)\right| \leqslant\left|\phi_{n}(t)-\prod_{i=1}^{3} \phi_{n, i}(t)\right|+\left|\prod_{i=1}^{3} \phi_{n, i}(t)-\exp \left(-\frac{V t^{2}}{2}\right)\right|$.

So we have two terms to evaluate.

(i) A bound for $\left|\phi_{n}(t)-\prod_{i=1}^{3} \phi_{n, i}(t)\right|$ is given from the following lemma.

Lemma 2. If the centered sequence $\left(X_{n}\right)_{n \in \mathbf{N}}$ is (AG), then for any $l \in] 1, n[$,

$$
\left|\operatorname{cov}\left(\exp \left(i t S_{l}\right), \exp \left(i t\left(S_{n}-S_{l}\right)\right)\right)\right| \leqslant 4 t^{2} \sup _{i} \sum_{j=1}^{\infty} \min (j, n)\left|\operatorname{cov}\left(\tilde{X}_{i}, \tilde{X}_{i+j}\right)\right| .
$$

P r o of. The (AG) property applied with $h\left(x_{1}, \ldots, x_{l}\right)=f\left(t\left(x_{1}+\cdots+\right.\right.$ $\left.\left.x_{l}\right)\right), k\left(x_{l+1}, \ldots, x_{n}\right)=f\left(t\left(x_{l+1}+\cdots+x_{n}\right)\right)(f(x)$ is either $\cos x$ or $\sin x)$ yields

$$
\begin{aligned}
\left|\operatorname{cov}\left(\exp \left(i t S_{l}\right), \exp \left(i t\left(S_{n}-S_{l}\right)\right)\right)\right| & \leqslant 4 t^{2} \sum_{j=1}^{l} \sum_{i=l+1}^{n}\left|\operatorname{cov}\left(\tilde{X}_{i}, \tilde{X}_{j}\right)\right| \\
& \leqslant 4 t^{2} \sup _{i} \sum_{j=1}^{\infty} \min (j, n)\left|\operatorname{cov}\left(\tilde{X}_{i}, \tilde{X}_{i+j}\right)\right| .
\end{aligned}
$$

We deduce from Lemmas 1 and 2 that $\left|\phi_{n}(t)-\prod_{i=1}^{3} \phi_{n, i}(t)\right|$ has an order $O\left(t^{2} n^{1-\delta}\right)$ (respectively, $O\left(t^{2} n \ln ^{-p} n\right)$ and $\left.O\left(t^{2}\right)\right)$ if the (AG) sequence satisfies (3) (respectively, (4) and (2)).

(ii) In order to bound $\left|\prod_{i=1}^{3} \phi_{n, i}(t)-\exp \left(-V t^{2} / 2\right)\right|$, we shall use the following propositions.

Proposition 3. Let $\left(X_{n}\right)_{n \in \mathbf{N}}$ be a sequence of centered r.v. 's satisfying condition (8). Suppose that $\left(X_{n}\right)_{n \in \mathbf{N}}$ is bounded by $M$ and satisfies the (AG) property. Then there exists a positive constant $C$ such that for any $t \in$ ] $\left.\left.\left.0, \sigma^{-1}\right], \delta \in\right] 0,1\right]$ and $n \geqslant n_{0}$,

$$
\left|\phi_{n}(t)-\exp \left(-\frac{V_{n} t^{2}}{2}\right)\right| \leqslant C \sup _{k} \sum_{i=1}^{k-1} \min (M|t|(i+1), 1)\left|\operatorname{cov}\left(\tilde{X}_{k}, \tilde{X}_{k-i}\right)\right| .
$$

We deduce from Proposition 3, that the left-hand side of (19) is of order $O\left(t^{\delta}\right)$ (respectively, $O\left(|\ln t|^{-p}\right)$ ) if condition (3) (respectively, (4)) is satisfied.

For unbounded sequences of associated r.v.'s, we obtain the following. 
Proposition 4. Suppose that all the assumptions of Theorem 2 hold for $\rho>0$ and $q$ in $] 1,1+\rho[$. Then there exists a positive constant $C$ such that for any $\left.t \in] 0, \sigma^{-1}\right]$ and for any $n \geqslant n_{0}$,

$$
\left|\phi_{n}(t)-\exp \left(-\frac{V_{n} t^{2}}{2}\right)\right| \leqslant C t^{(2+\rho) /(3+\rho)} .
$$

Let us come back to the proof of Theorems 1 and 2 (the proof of Propositions 3 and 4 is given in the Subsection 3.1.1).

We suppose first that the sequence is (AG) and that (3) holds; then inequality (3.11) of [21] yields, for any $\left.t \in] 0, \sigma^{-1}\right]$,

$$
\left|\prod_{i=1}^{3} \phi_{n, i}(t)-\exp \left(-\frac{V t^{2}}{2}\right)\right| \leqslant C\left\{t^{3 \delta}+t^{\delta} \exp \left(-\frac{t^{2} n \sigma^{2}}{4}\right)\right\} .
$$

Hence, we obtain from a previous bound $\left|\phi_{n}(t)-\exp \left(-V t^{2} / 2\right)\right| \leqslant C\left\{t^{3 \delta}+\right.$ $\left.t^{\delta} \exp \left(-t^{2} n \sigma^{2} / 4\right)+t^{2} n^{1-\delta}\right\}$.

The last inequality together with (17) yields:

$$
\sup _{x \in \mathbf{R}}\left|\mathbf{P}\left\{S_{n} \leqslant x\right\}-\psi\left(\frac{x}{\sqrt{V}}\right)\right| \leqslant C\left(T^{3 \delta}+T^{2} n^{1-\delta}+n^{-\delta / 2}+\frac{1}{T \sqrt{n}}\right) .
$$

Thus the bound (9) is obtained with $T=n^{-1 / 2+\delta / 3}$.

We suppose now that the (AG) sequence satisfy (ii) of Theorem 1 . Then (19) together with (17) and (3.11), (3.21) of [21], yields for $n$ large enough and for $T \geqslant n^{-1 / 2}$,

$$
\sup _{x \in \mathbf{R}}\left|\mathbf{P}\left\{S_{n} \leqslant x\right\}-\psi\left(\frac{x}{\sqrt{V}}\right)\right| \leqslant C\left(\frac{1}{T \sqrt{n}}+\frac{T^{2} n}{\ln ^{p} n}+\ln ^{-p} n+\frac{\ln \left(n T^{2}\right)}{|\ln T|^{3 p}}\right) .
$$

So, we get the bound (10) if we take $T=\left(\ln ^{p / 3} n\right) / \sqrt{n}$ in the last inequality.

Finally, suppose that the sequence is associated and assume that all the conditions of Theorem 2 hold. Then, as before, (3.11) of [21] together with (20) and (17) yield:

$$
\begin{aligned}
& \sup _{x \in \mathbf{R}}\left|\mathbf{P}\left\{S_{n} \leqslant x\right\}-\psi\left(\frac{x}{\sqrt{V}}\right)\right| \\
& \leqslant C\left(T^{3(2+\rho) /(3+\rho)}+T^{2}+n^{-(2+\rho) / 2(3+\rho)}+\frac{1}{T \sqrt{n}}\right) .
\end{aligned}
$$

Hence the bound (12) follows with $T=n^{-1 / 6}$.

3.1.1. Proof of Propositions 3 and 4. We have, for all $n \geqslant n_{0}$ :

$$
\begin{aligned}
& \left|\phi_{n}(t)-\exp \left(-\frac{V_{n} t^{2}}{2}\right)\right| \\
& \quad \leqslant \sum_{k=1}^{n} \exp \left(-\frac{\left(V_{n}-V_{k}\right) t^{2}}{2}\right)\left|\phi_{k}(t)-\exp \left(-\frac{v_{k} t^{2}}{2}\right) \phi_{k-1}(t)\right| \\
& \quad \leqslant C_{\sigma}\left(t^{-2} \wedge n\right) \max _{k \leqslant n}\left|\phi_{k}(t)-\exp \left(-\frac{v_{k} t^{2}}{2}\right) \phi_{k-1}(t)\right| .
\end{aligned}
$$


Clearly,

$$
\begin{aligned}
\max _{k \leqslant n}\left|\phi_{k}(t)-\exp \left(-\frac{v_{k} t^{2}}{2}\right) \phi_{k-1}(t)\right| \leqslant \max _{k \leqslant n}\left|\phi_{k}(t)-\left(1-\frac{v_{k} t^{2}}{2}\right) \phi_{k-1}(t)\right| \\
+\max _{k \leqslant n}\left|\exp \left(-\frac{v_{k} t^{2}}{2}\right)-\left(1-\frac{v_{k} t^{2}}{2}\right)\right| .
\end{aligned}
$$

Hence Proposition 2 applied when $f(x)$ is either $\cos (t x)$ or $\sin (t x)$, implies that the quantity $\left|\phi_{k}(t)-\left(1-v_{k} t^{2} / 2\right) \phi_{k-1}(t)\right|$ is of order $O\left(t^{2+(2+\rho) /(3+\rho)}\right)$ if the sequence is associated and if (8), (11) and (2) are satisfied. For (AG) sequences fulfilling condition (8), Proposition 2 yields the bound:

$$
\begin{aligned}
& \max _{k \leqslant n}\left|\phi_{k}(t)-\left(1-\frac{v_{k} t^{2}}{2}\right) \phi_{k-1}(t)\right| \\
& \quad \leqslant C t^{2} \max _{k \leqslant n} \sum_{i=1}^{k-1} \min (1,|t|(i+1) M)\left|\operatorname{cov}\left(\tilde{X}_{k}, \tilde{X}_{k-i}\right)\right| .
\end{aligned}
$$

Propositions 3 and 4 follow then if we prove that the quantity $\left|\exp \left(-v_{k} t^{2} / 2\right)-\left(1-v_{k} t^{2} / 2\right)\right|$ has a same order as $\left|\phi_{k}(t)-\left(1-v_{k} t^{2} / 2\right) \phi_{k-1}(t)\right|$. For this we use the following lemma.

Lemma 3 (see [21]). If $|v| \leqslant x+y$, for some $x, y \geqslant 0$, then $\mid \exp (v)-$ $1-v \mid \leqslant\left(x+y^{2} / 2\right) \sup (1, \exp (v))$.

Now, let $t$ be a positive real number. Clearly

$$
\begin{aligned}
v_{k}= & \left(\mathbf{E} X_{k}^{2} \mathbf{1}_{\left|X_{k}\right| \leqslant t^{-1}}+2 \sum_{i=1}^{k-1} \mathbf{1}_{i\|X\|_{2}|t| \leqslant 1} \operatorname{cov}\left(X_{k}, X_{k-i}\right)\right) \\
& +\left(\mathbf{E} X_{k}^{2} \mathbf{1}_{\left|X_{k}\right|>t^{-1}}+2 \sum_{i=1}^{k-1} \mathbf{1}_{i\|X\|_{2}|t|>1} \operatorname{cov}\left(X_{k}, X_{k-i}\right)\right)=: y_{k}+x_{k} .
\end{aligned}
$$

We first give a bound for $x_{k}$. It is easily seen that,

$$
\begin{aligned}
x_{k} & \leqslant \mathbf{E} X_{k}^{2} \min \left(1,|t|\left|X_{k}\right|\right)+\sum_{i=1}^{k-1} \min \left(1,|t|(i+1)\|X\|_{2}\right)\left|\operatorname{cov}\left(X_{k}, X_{k-i}\right)\right| \\
& =: M_{3, k}\left(t,\|X\|_{2}\right),
\end{aligned}
$$

also,

$$
y_{k}^{2} t^{4} \leqslant 4 t^{4}\left(\left(\mathbf{E} X_{k}^{2} 1_{\left|X_{k}\right| \leqslant t^{-1}}\right)^{2}+\left(\sum_{i=1}^{k-1} \mathbf{1}_{i\|X\|_{2}|t| \leqslant 1} \operatorname{cov}\left(X_{k}, X_{k-i}\right)\right)^{2}\right)
$$

On the one hand, the Hölder inequality yields:

$$
\begin{aligned}
\left(\mathbf{E} X_{k}^{2} \mathbf{1}_{\left|X_{k}\right| \leqslant t^{-1}}\right)^{2} & \leqslant \mathbf{E} X_{k}^{4} \mathbf{1}_{\left|X_{k}\right| \leqslant t^{-1}} \leqslant|t|^{-1} \mathbf{E}\left|X_{k}\right|^{3} \mathbf{1}_{\left|X_{k}\right| \leqslant|t|^{-1}} \\
& \leqslant|t|^{-2} \mathbf{E}\left|X_{k}\right|^{2} \min \left(\left|X_{k}\right||t|, 1\right) .
\end{aligned}
$$


On the other hand (denoting by $\|X\|_{2}=\sup _{i}\left\|X_{i}\right\|_{2}$ ),

$$
\begin{aligned}
& \left(\sum_{i=1}^{k-1} 1_{i\|X\|_{2}|t| \leqslant 1} \operatorname{cov}\left(X_{k}, X_{k-i}\right)\right)^{2} \\
& \leqslant 2\|X\|_{2}^{2} \sum_{j=1}^{k-1} \sum_{i=1}^{j} 1_{j\|X\|_{2}|t| \leqslant 1}\left|\operatorname{cov}\left(X_{k}, X_{k-j}\right)\right| \\
& \leqslant 2\|X\|_{2}^{2} \sum_{j=1}^{k-1} j \mathbf{1}_{j\|X\|_{2}|t| \leqslant 1}\left|\operatorname{cov}\left(X_{k}, X_{k-j}\right)\right| \\
& \leqslant 2|t|^{-2} \sum_{j=1}^{k-1} j|t|\|X\|_{2} \mathbf{1}_{j\|X\|_{2}|t| \leqslant 1}\left|\operatorname{cov}\left(X_{k}, X_{k-j}\right)\right| \\
& \leqslant 2|t|^{-2} \sum_{j=1}^{k-1} \min \left(j|t|\|X\|_{2}, 1\right)\left|\operatorname{cov}\left(X_{k}, X_{k-j}\right)\right| .
\end{aligned}
$$

The previous inequalities, together with Lemma 3, yield

$$
\begin{aligned}
& \left|\exp \left(-\frac{v_{k} t^{2}}{2}\right)-\left(1-\frac{v_{k} t^{2}}{2}\right)\right| \leqslant t^{2} M_{3, k}\left(t,\|X\|_{2}\right) \\
& \leqslant t^{2} \sum_{i=1}^{k-1} \min \left(t\|X\|_{2}(i+1), 1\right)\left|\operatorname{cov}\left(X_{k}, X_{k-i}\right)\right| .
\end{aligned}
$$

The last inequality together with inequalities (21)-(23) complete the proof of Propositions 3 and 4.

3.2. Estimation of the Dudley distance. Let $\left(Y_{i}\right)_{i \in \mathbf{N}}$ be a centered sequence of independent and normal r.v.'s. For (AG) sequences, we suppose that $\mathbf{D} Y_{i}=V_{n} / n$ for all $i$. While for associated sequences, we suppose that $\mathrm{D} Y_{i}=v_{i}$ (recall that the association property yields $v_{i}=V_{i}-V_{i-1} \geqslant 0$ ).

Assume furthermore that $\left(Y_{i}\right)_{i \in \mathbf{N}}$ is independent of $\left(X_{i}\right)_{i \in \mathbf{N}}$. For any $k \in[0, n]$, let $T_{k+1, n}=\sum_{i=k+1}^{n} Y_{i}$, with the convention that $T_{n+1, n}=0$, where $T_{n}=Y_{1}+\cdots+Y_{n}$. Let $f \in \mathscr{F}\left(b_{2}, b_{3}\right)$. Clearly, $\mathbf{D} T_{n}=V_{n}$ and $\mathbf{E}\left(f\left(S_{n}\right)-f\left(T_{n}\right)\right)=\sum_{k=1}^{n}\left[\Delta_{1, k}(f)-\Delta_{2, k}(f)\right]$, where

$$
\begin{gathered}
\Delta_{1, k}(f)=\mathbf{E}\left[f\left(S_{k-1}+X_{k}+T_{k+1, n}\right)-f\left(S_{k-1}+T_{k+1, n}\right)\right. \\
\left.-\frac{v_{k}}{2} f^{\prime \prime}\left(S_{k-1}+T_{k+1, n}\right)\right], \\
\Delta_{2, k}(f)=\mathbf{E}\left[\begin{array}{l}
f\left(S_{k-1}+Y_{k}+T_{k+1, n}\right)-f\left(S_{k-1}+T_{k+1, n}\right) \\
\left.-\frac{v_{k}}{2} f^{\prime \prime}\left(S_{k-1}+T_{k+1, n}\right)\right] .
\end{array}\right.
\end{gathered}
$$

C o n t r o 1 of $\left|\Delta_{2, k}(f)\right|$. Since $\left(Y_{i}\right)_{i \in \mathbf{N}}$ is independent of $\left(X_{i}\right)_{i \in \mathbf{N}}$, Taylor's formula yields:

$$
\left|\Delta_{2, k}(f)\right| \leqslant b_{3} \mathbf{E}\left|Y_{k}\right|^{3}+b_{2}\left|v_{k}-\mathbf{E} Y_{k}^{2}\right| .
$$


When $Y_{k}$ is a normal law with $\mathbf{D} Y_{k}=V_{n} / n$ and $\mathbf{E} Y_{k}=0$, there holds

$$
\left|\Delta_{2, k}(f)\right| \leqslant C\left(b_{3}\left(\frac{V_{n}}{n}\right)^{3 / 2}+\frac{b_{2}}{n}\left|n v_{k}-V_{n}\right|\right) .
$$

If moreover $\left(X_{i}\right)_{i \in \mathbf{N}}$ is a weakly stationary sequence, then $\left|n v_{k}-V_{n}\right| \leqslant$ $2 \sum_{r=1}^{n-1}\left(r+n \mathbf{1}_{r \geqslant k}\right)\left|\mathbf{E} X_{1} X_{1+r}\right|$ and $\sum_{k=1}^{n}\left|n v_{k}-V_{n}\right| \leqslant 4 n \sum_{r=1}^{n-1} r\left|\mathbf{E} X_{1} X_{1+r}\right|$. Hence we get for (AG) sequences:

$$
\sum_{k=1}^{n}\left|\Delta_{2, k}(f)\right| \leqslant C\left(b_{3} n\left(\frac{V_{n}}{n}\right)^{3 / 2}+b_{2} \sum_{r=1}^{n-1} r\left|\mathbf{E} X_{1} X_{1+r}\right|\right) .
$$

In the associated case, $Y_{k}$ is supposed to be a normal law with $\mathbf{D} Y_{k}=v_{k}$ and $\mathbf{E} Y_{k}=0$, then (24) yields: $\left|\Delta_{2, k}(f)\right| \leqslant C b_{3} v_{k}^{3 / 2}$. Hölder's inequality yields: $v_{k}^{3 / 2} \leqslant C \sum_{i=1}^{k-1} i \operatorname{cov}\left(X_{k}, X_{k-i}\right)$. Hence we obtain for associated sequences

$$
\sum_{k=1}^{n}\left|\Delta_{2, k}(f)\right| \leqslant C b_{3} n \sum_{i=1}^{n-1} i \sup _{k \geqslant i} \operatorname{cov}\left(X_{k}, X_{k-i}\right) .
$$

C o n t r o l of $\left|\Delta_{1, k}(f)\right|$. Since $T_{k+1, n}$ is independent of the sequence $\left(X_{i}\right)_{i \in \mathbf{N}}$, we obtain (using also Fubini's theorem and the invariance by translations of the class $\left.\mathscr{F}\left(b_{2}, b_{3}\right)\right)$

$$
\left|\Delta_{1, k}(f)\right| \leqslant \sup _{g \in \mathscr{F}\left(b_{2}, b_{3}\right)}\left|\Delta_{k}(g)\right|,
$$

where $\Delta_{k}(f)$ is defined by (14). Proposition 2 gives then bounds of $\left|\Delta_{k}(f)\right|$ for associated or (AG) sequences.

The proof of Theorems 3 and 4 follows then from the previous estimations with $b_{2}=V_{n}^{-1}$ and $b_{3}=V_{n}^{-3 / 2}$.

3.3. Proof of Proposition 1. The proof of this proposition follows from inequality (15) exactly as in the proof of Theorem 3 in [21].

Appendix: Proof of Proposition 2. The proof of Proposition 2 is done in two steps.

$\mathrm{S} t \mathrm{e}$ 1: The Lindeberg-Rio decomposition.

Lemma 4. If $\left(X_{n}\right)_{n \in \mathbf{N}}$ is a centered sequence of r.v.'s, then for any integer $a_{k}$ in $[1, k]$ and for all twice differentiable real-valued function $f$

$$
\begin{aligned}
\left|\Delta_{k}(f)\right| \leqslant & \left|\mathbf{E}\left(f\left(S_{k}\right)-f\left(S_{k-1}\right)-X_{k} f^{\prime}\left(S_{k-1}\right)-\frac{1}{2} X_{k}^{2} f^{\prime \prime}\left(S_{k-1}\right)\right)\right| \\
& +\left|\mathbf{E} X_{k} f^{\prime}\left(S_{k-a_{k}}\right)\right| \\
& +\sum_{i=1}^{a_{k}-1}\left|\operatorname{cov}\left(X_{k}, X_{k-i} \int_{0}^{1}\left[f^{\prime \prime}\left(S_{k-i-1}+u X_{k-i}\right)-f^{\prime \prime}\left(S_{k-i-1}\right)\right] d u\right)\right| \\
& +\sum_{i=1}^{a_{k}-1}\left|\operatorname{cov}\left(X_{k}, X_{k-i}\left[f^{\prime \prime}\left(S_{k-i-1}\right)-f^{\prime \prime}\left(S_{k-2 i-1}\right)\right]\right)\right|
\end{aligned}
$$




$$
\begin{aligned}
& +\sum_{i=1}^{a_{k}-1} \mid\left(\operatorname{cov}\left(X_{k} X_{k-i}, f^{\prime \prime}\left(S_{k-2 i-1}\right)\right)\left|+\frac{1}{2}\right| \operatorname{cov}\left(X_{k}^{2}, f^{\prime \prime}\left(S_{k-1}\right)\right) \mid\right. \\
& +\left|\sum_{i=1}^{a_{k}-1} \mathbf{E} X_{k} X_{k-i} \mathbf{E} f^{\prime \prime}\left(S_{k-2 i-1}\right)-\sum_{i=1}^{k-1} \mathbf{E} X_{k} X_{k-i} \mathbf{E} f^{\prime \prime}\left(S_{k-1}\right)\right| .
\end{aligned}
$$

Lemma 4 follows using the relations $g\left(S_{n}\right)-g(0)=\sum_{k=1}^{n}\left[g\left(S_{k}\right)-\right.$ $\left.g\left(S_{k-1}\right)\right]$ and $g\left(S_{k}\right)-g\left(S_{k-1}\right)=X_{k} \int_{0}^{1} g^{\prime}\left(S_{k-1}+u X_{k}\right) d u$, for convenient functions $g$.

$\mathrm{S}$ t e p 2: Covariance inequalities. Now we evaluate the covariance quantities of Lemma 4. We will use repeatedly the following inequalities:

$$
x \mathbf{1}_{x \leqslant 1} \leqslant \min (x, 1), \quad \mathbf{1}_{1 \leqslant x} \leqslant \min (x, 1) \text { for } x \geqslant 0 .
$$

1. $\mathrm{P} \mathrm{r}$ o of of (15). Suppose here that the sequence $\left(X_{n}\right)_{n \in \mathbf{N}}$ is (AG) and bounded by $M$. Let $a_{k}$ (defined in Lemma 4) equal to $\min \left(b_{2} b_{3}^{-1} M^{-1}, k\right)$.

It follows from Taylor's formula and the (AG) property that:

$$
\begin{aligned}
& \left|\mathbf{E}\left(f\left(S_{k}\right)-f\left(S_{k-1}\right)-X_{k} f^{\prime}\left(S_{k-1}\right)-\frac{1}{2} X_{k}^{2} f^{\prime \prime}\left(S_{k-1}\right)\right)\right| \\
& \quad \leqslant \mathbf{E} X_{k}^{2} \min \left(b_{2}, b_{3}\left|X_{k}\right|\right) \leqslant\left(b_{2} \wedge b_{3} M\right) \mathbf{D} \tilde{X}_{k} .
\end{aligned}
$$

Now we apply the (AG) property with $k\left(x_{1}, \ldots, x_{k-1}\right)=f^{\prime \prime}\left(x_{1}+\cdots+x_{k-1}\right)$ and with a function $h$ (with bounded first derivative) that equals to $x^{2}$ if $|x| \leqslant M$ and to a suitable constant otherwise. We obtain

$$
\begin{aligned}
\left|\operatorname{cov}\left(X_{k}^{2}, f^{\prime \prime}\left(S_{k-1}\right)\right)\right| & \leqslant 2 \min \left(b_{2} \mathbf{E} X_{k}^{2}, b_{3} M \sum_{i=1}^{k-1}\left|\operatorname{cov}\left(\tilde{X}_{k}, \tilde{X}_{k-i}\right)\right|\right) \\
& \leqslant 2 \min \left(b_{2}, b_{3} M\right) \sum_{i=0}^{k-1}\left|\operatorname{cov}\left(\tilde{X}_{k}, \tilde{X}_{k-i}\right)\right| .
\end{aligned}
$$

In a similar way, the (AG) property yields

$$
\begin{aligned}
& \left|\mathbf{E} X_{k} f^{\prime}\left(S_{k-a_{k}}\right)\right| \leqslant b_{2} \sum_{i=a_{k}}^{k-1}\left|\operatorname{cov}\left(\tilde{X}_{k}, \tilde{X}_{k-i}\right)\right| \\
& \quad \leqslant \sum_{i=1}^{k-1} b_{2} \mathbf{1}_{b_{2} b_{3}^{-1} M^{-1} \leqslant i}\left|\operatorname{cov}\left(\tilde{X}_{k}, \tilde{X}_{k-i}\right)\right| \leqslant \sum_{i=1}^{k-1} \min \left(b_{2}, i M b_{3}\right)\left|\operatorname{cov}\left(\tilde{X}_{k}, \tilde{X}_{k-i}\right)\right|,
\end{aligned}
$$

also,

$$
\begin{aligned}
& \sum_{i=1}^{a_{k}-1} \int_{0}^{1}\left|\operatorname{cov}\left(X_{k}, X_{k-i}\left[f^{\prime \prime}\left(S_{k-i-1}+u X_{k-i}\right)-f^{\prime \prime}\left(S_{k-i-1}\right)\right]\right)\right| d u \\
& \leqslant 2 M b_{3} \sum_{i=1}^{a_{k}-1}\left(\left|\operatorname{cov}\left(\tilde{X}_{k}, \tilde{X}_{k-i}\right)\right|+\sum_{j=i+1}^{k-1}\left|\operatorname{cov}\left(\tilde{X}_{k}, \tilde{X}_{k-j}\right)\right|\right) \\
& \leqslant 2 M b_{3} \sum_{i=1}^{k-1} \mathbf{1}_{i \leqslant b_{2} b_{3}^{-1} M^{-1}}\left(\left|\operatorname{cov}\left(\tilde{X}_{k}, \tilde{X}_{k-i}\right)\right|+\sum_{j=i+1}^{k-1}\left|\operatorname{cov}\left(\tilde{X}_{k}, \tilde{X}_{k-j}\right)\right|\right)
\end{aligned}
$$




$$
\begin{aligned}
& \leqslant \sum_{i=1}^{k-1} \sum_{j=i}^{k-1} 2 M b_{3} \mathbf{1}_{i \leqslant b_{2} b_{3}^{-1} M^{-1}}\left|\operatorname{cov}\left(\tilde{X}_{k}, \tilde{X}_{k-j}\right)\right| \\
& \leqslant \sum_{j=1}^{k-1} 2 \min \left(M b_{3} j, b_{2}\right)\left|\operatorname{cov}\left(\tilde{X}_{k}, \tilde{X}_{k-j}\right)\right| .
\end{aligned}
$$

In the same way, we bound the quantities

$$
\begin{aligned}
& \sum_{i=1}^{a_{k}-1}\left|\operatorname{cov}\left(X_{k}, X_{k-i}\left[f^{\prime \prime}\left(S_{k-i-1}\right)-f^{\prime \prime}\left(S_{k-2 i-1}\right)\right]\right)\right|, \\
& \sum_{i=1}^{a_{k}-1}\left|\operatorname{cov}\left(X_{k} X_{k-i}, f^{\prime \prime}\left(S_{k-2 i-1}\right)\right)\right| .
\end{aligned}
$$

Inequality (15) follows if we bound the last quantity of (25). For this write

$$
\begin{aligned}
& \left|\sum_{i=1}^{a_{k}-1} \mathbf{E} X_{k} X_{k-i} \mathbf{E} f^{\prime \prime}\left(S_{k-2 i-1}\right)-\sum_{i=1}^{k-1} \mathbf{E} X_{k} X_{k-i} \mathbf{E} f^{\prime \prime}\left(S_{k-1}\right)\right| \\
& \quad=\left|\sum_{i=1}^{k-1} \mathbf{E} X_{k} X_{k-i}\left(\mathbf{1}_{i \leqslant b_{2} b_{3}}{ }^{-1} M^{-1} \mathbf{E} f^{\prime \prime}\left(S_{k-2 i-1}\right)-\mathbf{E} f^{\prime \prime}\left(S_{k-1}\right)\right)\right| \\
& \quad \leqslant \sum_{i=1}^{k-1}\left|\mathbf{E} X_{k} X_{k-i}\right| \min \left(b_{2}, b_{3} M i\right) \\
& \quad \leqslant \sum_{i=1}^{k-1}\left|\operatorname{cov}\left(\tilde{X}_{k}, \tilde{X}_{k-i}\right)\right| \min \left(b_{2}, b_{3} M i\right),
\end{aligned}
$$

the last inequalities are obtained from the (AG) property and from the fact

$$
\left|\mathbf{1}_{i \leqslant b_{2} b_{3}{ }^{-1} M^{-1}} \mathbf{E} f^{\prime \prime}\left(S_{k-2 i-1}\right)-\mathbf{E} f^{\prime \prime}\left(S_{k-1}\right)\right| \leqslant \min \left(b_{2}, b_{3} M i\right) .
$$

Now, inequalities (27)-(30), together with (25), yield the bound (15).

2. $\mathrm{P} \mathrm{r}$ o of of (16). We suppose now that the sequence $\left(X_{n}\right)_{n \in \mathrm{N}}$ is associated.

For a positive real number $x$, we define the functions $Z_{i}(x):=Z_{X_{i}}(x):=$ $\mathbf{1}_{X_{i} \geqslant x}-\mathbf{1}_{X_{i} \leqslant-x}$ and $Z(x):=Z_{X}(x)$. Let $X^{+}=\max (0, X)$ and $X^{-}=$ $\max (0,-X)$. Then

$$
\begin{gathered}
X=X^{+}-X^{-}=\int_{0}^{\infty}\left[\mathbf{1}_{X^{+} \geqslant x}-\mathbf{1}_{X^{-} \geqslant x}\right] d x=\int_{0}^{\infty} Z(x) d x \text { and } \\
|Z(x)| \leqslant 1, \quad \mathbf{E}|Z(x)|=\mathbf{P}\{|X| \geqslant x\},
\end{gathered}
$$

these last inequalities will be used on several occasions. We note also that $Z(x)$ is a nondecreasing function of the r.v. $X$. Hence by $\left(\mathscr{P}_{4}\right)$ of [13] the vector $(Z(x), Y, X)$ is associated whenever $(X, Y)$ fulfills the association property.

The following two lemmas are the main tools for the proof of (16). 
Lemma 5. Let $\left(X_{1}, X_{2}\right)$ be an associated random vector. Let $p$ and $\delta$ be some fixed positive real numbers such that $1<p<\delta^{-1}$. If $\|X\|_{\alpha}:=$ $\max \left(\left\|X_{1}\right\|_{\alpha},\left\|X_{2}\right\|_{\alpha}\right)<\infty$, for $\alpha>2(1-p \delta)^{-1}$, then there exists a positive constant $C_{p, \delta, \alpha}$ that depends only on $p, \delta$ and $\alpha$ such that

$$
\int_{0}^{\infty} \int_{0}^{\infty} \operatorname{cov}^{1-\delta}\left(Z_{1}(x), Z_{2}(y)\right) d x d y \leqslant C_{p, \delta, \alpha}\|X\|_{\alpha}^{2 / p} \operatorname{cov}^{1-1 / p}\left(X_{1}, X_{2}\right) .
$$

Suppose now that $\left\|X_{2}\right\|_{\alpha}<\infty,\left\|X_{1}\right\|_{\gamma}<\infty$ for some $\alpha>1$ and $\gamma>$ $\alpha[(\alpha-1)(1-p \delta)]^{-1}$, then there exists a positive constant $C_{p, \alpha}$ that depends only on $p$ and $\alpha$ for which

$$
\int_{0}^{\infty} \operatorname{cov}^{1-\delta}\left(Z_{1}(x), X_{2}\right) d x \leqslant C_{p, \alpha}\left\|X_{2}\right\|_{\alpha}^{1 / p-\delta}\left\|X_{1}\right\|_{\gamma}^{1 / p} \operatorname{cov}^{1-1 / p}\left(X_{1}, X_{2}\right) .
$$

Lemma 6. Let $\left(X_{1}, X_{2}\right)$ be an associated random vector. Let $X_{3}$ be an arbitrary r.v.'s such that $\left\|X_{3}\right\|_{q}<+\infty$, for some $q>1$. Then there exists a constant $C_{q, p, \alpha}$ such that for any positive real numbers $A_{1}, A_{2}$

$$
\begin{aligned}
& \int_{0}^{\infty} \int_{0}^{\infty} \min \left(A_{1} \mathbf{P}\left\{\left|X_{3}\right|>z\right\}, A_{2} \operatorname{cov}\left(Z_{1}(x), X_{2}\right)\right) d x d z \\
& \quad \leqslant C_{q, p, \alpha} A_{1}^{1 / q} A_{2}^{1-1 / q}\left\|X_{1}\right\|_{\gamma}^{1 / p}\left\|X_{2}\right\|_{\alpha}^{1 / p-1 / q}\left\|X_{3}\right\|_{q} \operatorname{cov}^{1-1 / p}\left(X_{1}, X_{2}\right),
\end{aligned}
$$

where $1<p<q, \alpha>1$ and $\gamma>\alpha[(\alpha-1)(1-p / q)]^{-1}$.

We prove Lemmas 5 and 6 at the end of the paper and we continue the proof of inequality (16). Lemma 5 applied with $\delta=(3+\rho)^{-1}$ and $\alpha=3+\rho$ implies for some $p:=q \in] 1,1+\rho[$ :

$$
\begin{aligned}
& \|X\|_{3+\rho} \int_{0}^{\infty} \int_{0}^{\infty} \operatorname{cov}^{(2+\rho) /(3+\rho)}\left(Z_{k}(x), Z_{k-i}(y)\right) d x d y \\
& \quad \leqslant C_{\rho}\|X\|_{3+\rho}^{1+2 / q} \operatorname{cov}^{1-1 / q}\left(X_{k}, X_{k-i}\right) .
\end{aligned}
$$

In the same way, Lemma 6 applied with $\alpha=q=\gamma=3+\rho$ implies for some $p$ in $] 1,(3+\rho)(1+\rho) /(2+\rho)[$ :

$$
\begin{aligned}
& \int_{0}^{\infty} \int_{0}^{\infty} \min \left(b_{2} \mathbf{P}\left\{\left|X_{k-i}\right| \geqslant y\right\}, b_{3} \operatorname{cov}\left(Z_{k}(x), S_{k-i}\right)\right) d x d y \\
& \leqslant C_{\rho} b_{2}^{1 /(3+\rho)} b_{3}^{(2+\rho) /(3+\rho)}\|X\|_{3+\rho}^{2 / p+(2+\rho) /(3+\rho)} \sum_{j=i}^{k-1} \operatorname{cov}^{1-1 / p}\left(X_{k}, X_{k-j}\right) .
\end{aligned}
$$

In order to prove (16), it suffices then to bound the covariance quantities of Lemma 4 by the left-hand side of (35) and (36). For this we suppose in the sequel that $a_{k}=k$ (recall that $a_{k}$ is defined in Lemma 4).

Control of $A_{1}:=\left|\operatorname{cov}\left(X_{k}, X_{k-i}\left[f^{\prime \prime}\left(S_{k-i-1}+u X_{k-i}\right)-f^{\prime \prime}\left(S_{k-i-1}\right)\right]\right)\right|$.

It follows clearly from Fubini's theorem and from the integral representation (31) that:

$$
\begin{aligned}
& \operatorname{cov}\left(X_{k}, X_{k-i}\left[f^{\prime \prime}\left(S_{k-i-1}+u X_{k-i}\right)-f^{\prime \prime}\left(S_{k-i-1}\right)\right]\right) \\
& =\int_{0}^{\infty} \int_{0}^{\infty} \operatorname{cov}\left(Z_{k}(x), Z_{k-i}(y)\left[f^{\prime \prime}\left(S_{k-i-1}+u X_{k-i}\right)-f^{\prime \prime}\left(S_{k-i-1}\right)\right]\right) d x d y
\end{aligned}
$$




$$
\begin{aligned}
=\int_{0}^{\infty} \int_{0}^{\infty}\{\operatorname{cov}( & Z_{k}(x), Z_{k-i}(y) \\
& \left.\times\left[f^{\prime \prime}\left(S_{k-i-1}+u X_{k-i}\right)-f^{\prime \prime}\left(S_{k-i-1}+u \phi_{M}\left(X_{k-i}\right)\right)\right]\right) \\
+\operatorname{cov}\left(Z_{k}(x), Z_{k-i}(y)\right. & \left.\left.\times\left[f^{\prime \prime}\left(S_{k-i-1}+u \phi_{M}\left(X_{k-i}\right)\right)-f^{\prime \prime}\left(S_{k-i-1}\right)\right]\right)\right\} d x d y
\end{aligned}
$$

where $\phi_{M}$ is the nondecreasing function bounded by $M$ and defined by

$$
\phi_{M}(x):=x \mathbf{1}_{|x| \leqslant M}+M \mathbf{1}_{x \geqslant M}-M \mathbf{1}_{x \leqslant-M} .
$$

1. We bound first $I_{1}(x, y)$. Since $f \in \mathscr{F}\left(b_{2}, b_{3}\right)$, we obtain

$$
\begin{aligned}
\left|I_{1}(x, y)\right| & \leqslant 2 b_{3} \mathbf{E}\left|X_{k-i}-\phi_{M}\left(X_{k-i}\right)\right| \leqslant 2 b_{3} \mathbf{E}\left|X_{k-i}\right| \mathbf{1}_{\left|X_{k-i}\right| \geqslant M} \\
& \leqslant 2 b_{3} \frac{\left\|X_{k-i}\right\|_{3+\rho}^{3+\rho}}{M^{2+\rho}} .
\end{aligned}
$$

2. Now we evaluate $\left|I_{2}(x, y)\right|$. Since $f \in \mathscr{F}\left(b_{2}, b_{3}\right)$, (32) yields

$$
\left|I_{2}(x, y)\right| \leqslant 4 b_{2} \mathbf{P}\left\{\left|X_{k-i}\right| \geqslant y\right\} \text {. }
$$

Another bound of $\left|I_{2}(x, y)\right|$ follows from the association of the vector $\left(Z_{k}(x), Z_{k-i}(y), S_{k-i-1}, X_{k-i}\right)$, indeed the (AG) property applied with $h(x)=x$ and $k(x, y, z)=x\left[f^{\prime \prime}\left(y+u \phi_{M}(z)\right)-f^{\prime \prime}(y)\right]$ yields

$$
\left|I_{2}(x, y)\right| \leqslant b_{3} M \operatorname{cov}\left(Z_{k}(x), Z_{k-i}(y)\right)+2 b_{3} \operatorname{cov}\left(Z_{k}(x), S_{k-i}\right) \text {. }
$$

Both inequalities (39), (40) and the elementary bound $\min (a, c+d) \leqslant c+$ $\min (a, d)$, for $a, c, d \geqslant 0$, yield

$$
\begin{aligned}
\left|I_{2}(x, y)\right| \leqslant & \min \left(b_{2} \mathbf{P}\left\{\left|X_{k-i}\right| \geqslant y\right\}, b_{3} \operatorname{cov}\left(Z_{k}(x), S_{k-i}\right)\right) \\
& +b_{3} M \operatorname{cov}\left(Z_{k}(x), Z_{k-i}(y)\right) .
\end{aligned}
$$

Inequalities (38) and (41) yield then, if we choose

that

$$
M=\frac{\left\|X_{k-i}\right\|_{3+\rho}}{\operatorname{cov}^{1 /(3+\rho)}\left(Z_{k}(x), Z_{k-i}(y)\right)},
$$

$$
\begin{aligned}
A_{1} \leqslant & \int_{0}^{\infty} \int_{0}^{\infty} \min \left(b_{2} \mathbf{P}\left\{\left|X_{k-i}\right| \geqslant y\right\}, b_{3} \operatorname{cov}\left(Z_{k}(x), S_{k-i}\right)\right) d x d y \\
& +b_{3}\left\|X_{k-i}\right\|_{3+\rho} \int_{0}^{\infty} \int_{0}^{\infty} \operatorname{cov}^{(2+\rho) /(3+\rho)}\left(Z_{k}(x), Z_{k-i}(y)\right) d x d y .
\end{aligned}
$$
write

Control of $A_{2}:=\operatorname{cov}\left(X_{k}, X_{k-i}\left[f^{\prime \prime}\left(S_{k-i-1}\right)-f^{\prime \prime}\left(S_{k-2 i-1}\right)\right]\right)$. We

$$
\begin{aligned}
A_{2}= & \int_{0}^{\infty} \int_{0}^{\infty}\left\{\operatorname{cov}\left(Z_{k}(x), Z_{k-i}(y)\left[f^{\prime \prime}\left(S_{k-i-1}\right)-f^{\prime \prime}\left(S_{k-2 i-1}+\tilde{S}_{M}\right)\right]\right)\right. \\
& \left.\quad+\operatorname{cov}\left(Z_{k}(x), Z_{k-i}(y)\left[f^{\prime \prime}\left(S_{k-2 i-1}+\widetilde{S}_{M}\right)-f^{\prime \prime}\left(S_{k-2 i-1}\right)\right]\right)\right\} d x d y \\
= & : \int_{0}^{\infty} \int_{0}^{\infty}\left[I_{1}(x, y)+I_{2}(x, y)\right] d x d y,
\end{aligned}
$$


where $\widetilde{S}_{M}:=\sum_{j=k-2 i}^{k-i-1} \phi_{M}\left(X_{j}\right)$, we note that $\widetilde{S}_{M}$ is bounded by $i M$. As in (38), we obtain

$$
\left|I_{1}(x, y)\right| \leqslant 2 b_{3} i \sup _{k} \mathbf{E}\left|X_{k}-\phi_{M}\left(X_{k}\right)\right| \leqslant 2 b_{3} i \frac{\|X\|_{3+\rho}^{3+\rho}}{M^{2+\rho}} .
$$

By the same arguments as in (41), we obtain

$$
\begin{aligned}
\left|I_{2}(x, y)\right| \leqslant & \min \left(4 b_{2} \mathbf{P}\left\{\left|X_{k-i}\right| \geqslant y\right\}, b_{3} \operatorname{cov}\left(Z_{k}(x), S_{k-i}\right)\right) \\
& +2 b_{3} i M \operatorname{cov}\left(Z_{k}(x), Z_{k-i}(y)\right) .
\end{aligned}
$$

Hence we obtain for a suitable choice of $M$

$$
\begin{aligned}
\left|A_{2}\right| \leqslant & 2 b_{3} i\|X\|_{3+\rho} \int_{0}^{\infty} \int_{0}^{\infty} \operatorname{cov}^{(2+\rho) /(3+\rho)}\left(Z_{k}(x), Z_{k-i}(y)\right) d x d y \\
& +4 \int_{0}^{\infty} \int_{0}^{\infty} \min \left(b_{2} \mathbf{P}\left\{\left|X_{k-i}\right| \geqslant y\right\}, b_{3} \operatorname{cov}\left(Z_{k}(x), S_{k-i}\right)\right) d x d y .
\end{aligned}
$$

C on trol of $A_{3}:=\operatorname{cov}\left(X_{k} X_{k-i}, f^{\prime \prime}\left(S_{k-2 i-1}\right)\right)$. As before we write, $A_{3}=\int_{0}^{\infty} \int_{0}^{\infty} \operatorname{cov}\left(Z_{k}(x) Z_{k-i}(y), f^{\prime \prime}\left(S_{k-2 i-1}\right)\right) d x d y=: \int_{0}^{\infty} \int_{0}^{\infty} I_{3}(x, y) d x d y$. We provide two different bounds of the quantity $\left|I_{3}(x, y)\right|$. The first bound is $\left|I_{3}(x, y)\right| \leqslant 2 b_{2} \min \left(\mathbf{P}\left\{\left|X_{k}\right| \geqslant x\right\}, \mathbf{P}\left\{\left|X_{k-i}\right| \geqslant y\right\}\right)$. The second bound is obtained by using the association of the vector $\left(Z_{k}(x), Z_{k-i}(y), S_{k-2 i-1}\right)$ : the (AG) property applied with $h(x, y)=x y$ and with $k(x)=f^{\prime \prime}(x)$ yields $\left|I_{3}(x, y)\right| \leqslant b_{3} \operatorname{cov}\left(Z_{k}(x)+Z_{k-i}(y), S_{k-2 i-1}\right) \leqslant b_{3} \operatorname{cov}\left(Z_{k}(x)+Z_{k-i}(y), S_{k-i}\right)$. The previous two bounds of $\left|I_{3}(x, y)\right|$ and the elementary inequality $\min (a, b, e+f) \leqslant \min (a, e)+\min (b, f)$, for $a, b, e, f \geqslant 0$, yield:

$$
\begin{aligned}
\left|A_{3}\right| \leqslant & 2 \int_{0}^{\infty} \int_{0}^{\infty} \min \left(b_{2} \mathbf{P}\left\{\left|X_{k-i}\right| \geqslant y\right\}, b_{3} \operatorname{cov}\left(Z_{k}(x), S_{k-i}\right)\right) d x d y \\
& +2 \int_{0}^{\infty} \int_{0}^{\infty} \min \left(b_{2} \mathbf{P}\left\{\left|X_{k}\right| \geqslant x\right\}, b_{3} \operatorname{cov}\left(Z_{k-i}(y), S_{k-i}\right)\right) d x d y
\end{aligned}
$$

In the same way, we evaluate $\operatorname{cov}\left(X_{k}^{2}, f^{\prime \prime}\left(S_{k-1}\right)\right)$.

Control of $A_{4}:=\mathbf{E} X_{k} X_{k-i} \mathbf{E} f^{\prime \prime}\left(S_{k-2 i-1}\right)-\mathbf{E} X_{k} X_{k-i} \mathbf{E} f^{\prime \prime}\left(S_{k-1}\right)$. Clearly

$$
\left|A_{4}\right| \leqslant 2 \mathbf{E} X_{k} X_{k-i} \min \left(b_{2}, i b_{3} \mathbf{E}|X|\right)
$$

(here $\left.\mathbf{E}|X|=\sup _{i} \mathbf{E}\left|X_{i}\right|\right)$. Hence Lemma 4, together with inequalities (42), (44) -(46) and (35), (36) yields the proof of (16).

Let us now prove Lemmas 5 and 6.

$\mathrm{Pr}$ o of of $\mathrm{L} \mathrm{e} \mathrm{m} \mathrm{m} \mathrm{a} 5$. Hölder's inequality and some elementary estimations yield for any $p \in] 1, \delta^{-1}[$,

$$
\begin{aligned}
& \int_{0}^{\infty} \int_{0}^{\infty} \operatorname{cov}^{1-\delta}\left(Z_{1}(x), Z_{2}(y)\right) d x d y \\
& \leqslant \operatorname{cov}^{1-1 / p}\left(X_{1}, X_{2}\right)\left(\int_{0}^{\infty} \int_{0}^{\infty} \operatorname{cov}^{1-p \delta}\left(Z_{1}(x), Z_{2}(y)\right) d x d y\right)^{1 / p} \\
& \leqslant \operatorname{cov}^{1-1 / p}\left(X_{1}, X_{2}\right)
\end{aligned}
$$




$$
\begin{aligned}
& \times\left(\int_{0}^{\infty} \int_{0}^{\infty}\left[\min \left(\mathbf{P}\left\{\left|X_{1}\right| \geqslant x\right\}, \mathbf{P}\left\{\left|X_{2}\right| \geqslant y\right\}\right)\right]^{1-p \delta} d x d y\right)^{1 / p} \\
\leqslant & 2^{1 / p} \operatorname{cov}^{1-1 / p}\left(X_{1}, X_{2}\right)\left(\int_{0}^{\infty} x \mathbf{P}^{1-p \delta}\{|X| \geqslant x\} d x\right)^{1 / p}
\end{aligned}
$$

where $\mathbf{P}\{|X| \geqslant x\}=\max \left(\mathbf{P}\left\{\left|X_{1}\right| \geqslant x\right\}, \mathbf{P}\left\{\left|X_{2}\right| \geqslant x\right\}\right)$.

Suppose now that $\|X\|_{\alpha}<\infty$ for $\alpha>2(1-p \delta)^{-1}$, then for all $M>0$

$$
\begin{aligned}
\int_{0}^{\infty} x \mathbf{P}^{1-p \delta}\{|X| \geqslant x\} d x & \leqslant \frac{M^{2}}{2}+\int_{M}^{\infty} x \mathbf{P}^{1-p \delta}\{|X| \geqslant x\} d x \\
& \leqslant \frac{M^{2}}{2}+C \frac{\left(\mathbf{E}|X|^{\alpha}\right)^{1-p \delta}}{M^{\alpha(1-p \delta)-2}} .
\end{aligned}
$$

Hence if we choose $M=\|X\|_{\alpha}$ we obtain $\int_{0}^{\infty} x \mathbf{P}^{1-p \delta}\{|X| \geqslant x\} d x \leqslant C\|X\|_{\alpha}^{2}$, where $C$ is some positive constant depending only on $\delta, \alpha$ and $p$.

Inequality (33) is then obtained from the last inequality and from (47).

Now to prove (34), we use again Hölder's inequality

$$
\begin{aligned}
& \int_{0}^{\infty} \operatorname{cov}^{1-\delta}\left(Z_{1}(x), X_{2}\right) d x \\
& \quad \leqslant \operatorname{cov}^{1-1 / p}\left(X_{1}, X_{2}\right)\left(\int_{0}^{\infty} \operatorname{cov}^{1-p \delta}\left(Z_{1}(x), X_{2}\right) d x\right)^{1 / p} \\
& \quad \leqslant\left\|X_{2}\right\|_{\alpha}^{1 / p-\delta} \operatorname{cov}^{1-1 / p}\left(X_{1}, X_{2}\right)\left(\int_{0}^{\infty} \mathbf{P}^{(1-1 / \alpha)(1-p \delta)}\left\{\left|X_{1}\right| \geqslant x\right\} d x\right)^{1 / p} \\
& \quad \leqslant C_{\alpha, \delta, p}\left\|X_{2}\right\|_{\alpha}^{1 / p-\delta}\left\|X_{1}\right\|_{\gamma}^{1 / p} \operatorname{cov}^{1-1 / p}\left(X_{1}, X_{2}\right),
\end{aligned}
$$

which yields $(34)$ as soon as $\gamma>\alpha[(\alpha-1)(1-p \delta)]^{-1}$.

$\mathrm{P}$ r o of of L e m m a 6 . Clearly

$$
\begin{aligned}
\int_{0}^{\infty} & \int_{0}^{\infty} \min \left(A_{1} \mathbf{P}\left\{\left|X_{3}\right|>z\right\}, A_{2} \operatorname{cov}\left(Z_{1}(x), X_{2}\right)\right) d x d z \\
& \leqslant \int_{0}^{\infty} \int_{0}^{\infty} \min \left(A_{1}\left\|X_{3}\right\|_{q}^{q} z^{-q}, A_{2} \operatorname{cov}\left(Z_{1}(x), X_{2}\right)\right) d x d z .
\end{aligned}
$$

Writing the above integral as sums of integrals allows us to suppress the minimum and thus the quantity $(48)$ is bounded by

$$
C A_{1}^{1 / q} A_{2}^{1-1 / q}\left\|X_{3}\right\|_{q} \int_{0}^{\infty} \operatorname{cov}^{1-1 / q}\left(Z_{1}(x), X_{2}\right) d x .
$$

The proof of Lemma 6 follows then from the last bound and from (34).

\section{REFERENCES}

1. Birkel T. Momentenabschätzungen und grenzwertsätze für partialsummen assoziierter zufallsvariablen. Thesis. Cologne: Cologne University, 1986.

2. Birkel T. Moment bounds for associated sequences. - Ann. Probab., 1988, v. 16, № 3, p. 1184-1193. 
3. Birkel $T$. On the convergence rate in the central limit theorem for associated processes. - Ann. Probab., 1988, v. 16, № 4, p. 1685-1698.

4. Bulinskij A.V. On analogues of Berry-Esseen estimate for associated random fields. - Stability Problems for Stochastic Models. Ed. by V. M. Zolotarev et al. Moscow: TVP, 1994, p. 9-20.

5. Булинский $A . B$. Функциональный закон повторного логарифма для ассоциированных случайных полей. - Фунд. прикл. матем., 1995, т. 1, № 3, с. 623-639.

6. Булинский $A . B$. Скорость сходимости в центральной предельной теореме для полей ассоциированных величин. - Теория вероятн. и ее примен., 1995, т. 40, в. 1 , c. $165-174$.

7. Bulinski $A$. V. On the convergence rates in the CLT for positively and negatively dependent random fields. - Probability Theory and Mathematical Statistics, Ed. by I. A. Ibragimov et al. Amsterdam: Gordon and Breach, 1996, p. 3-14.

8. Dedecker J. A central limit theorem for stationary random fields. - Probab. Theory Relat. Fields, 1998, v. 110, № 3, p. 397-426.

9. Doukhan P. Mixing: Properties and Examples. Berlin: Springer-Verlag, 1994, 142 p.

10. Doukhan $P$., Portal $F$. Principe d'invariance faible avec vitesse pour un processus empirique dans un cadre multidimensionnel et mélangeant. - C. R. Acad. Sci. Paris Sér. I, v. 297, p. 505-508.

11. Doukhan P., Louhichi S. A new weak dependence condition and applications to moment inequalities. - Stochastic Process. Appl., 1999, v. 84, p. 313-342.

12. Doukhan P., Léon J.R. Cumulants for stationary mixing random sequences and applications to empirical spectral density. - Ann. Math. Statist., 1986, v. 10, p. 1126.

13. Esary J., Proschan F., Walkup D. Association of random variables with applications. - Ann. Math. Statist., 1967, v. 38, p. 1466-1476.

14. Joag-Dev K., Proschan F. Negative association of random variables, with applications. - Ann. Statist., 1982, v. 11, p. 286-295.

15. Lindeberg J. W. Eine neue Herleitung des Exponentialgeezetzes in der Wahrscheinlichkeitsrechnung. - Math. Z., 1922, v. 15, p. 211-225.

16. Newman C.M. Asymptotic independence and limit theorems for positively and negatively dependent random variables. - IMS Lecture Notes Monograph Ser., 1984, v. 5 , p. $127-140$.

17. Matula $P$. Probability and moment bounds for sums of negatively associated random variables. - Teor. Imovir. Mat. Statyst. 1996, v. 55, p. 130-135.

18. Petrov V. V. Limit Theorems of Probability Theory: Sequences of Independent Random Variables. Oxford: Clarendon Press, 1995, 292 p.

19. Rachev S. T. Probability Metrics and the Stability of Stochastic Models. Chichester: Wiley, 1991, $494 \mathrm{p}$.

20. Rio $E$. About the Lindeberg method for strongly mixing sequences. Prépublication 93.81. Paris: Université de Paris-Sud, 1993.

21. Rio $E$. About the Lindeberg method for strongly mixing sequences. - ESAIM Probab. Statist., 1995, v. 1, p. 35-61.

22. Rio $E$. Sur le théorème de Berry-Esseen pour les suites faiblement dépendantes. Probab. Theory Relat. Fields, 1996, v. 104, p. 255-282.

23. Rosenblatt $M$. A central limit theorem and a strong mixing condition. - Proc. Nat. Acad. Sci. U.S.A., 1956, v. 42, p. 43-47.

24. Shao $Q . M$., Yu $H$. Weak convergence for weighted empirical processes of dependent sequences. - Ann. Probab., 1996, v. 24, № 4, p. 2098-2127.

25. Врояский M. A. Скорость сходимости в УЗБЧ для ассоциированных последовательностей и полей. - Теория вероятн. и ее примен., 1998, т. 43, в. 3, с. 439-455.

26. Wood T.E. A Berry-Esseen theorem for associated random variables. - Ann. Probab., 1983, v. 11, p. 1042-1047. 